Vol. 40: 9-13, 2012

\title{
Study of root characters, leaf yield and yield components of mulberry under high and low soil moisture
}

\author{
N.K. Paul* and M.A. Qaiyyum \\ *Department of Botany, University of Rajshahi, Rajshah 6205, Bangladesh; \\ Bangladesh Sericulture Research and Training Institute, Rajshahi, Bangladesh. \\ *Corresponding author: nkpsg@yahoo.com
}

\begin{abstract}
Root characters, leaf yield and yield components of five mulberry varieties in relation to soil moisture i.e. well-watered, water- stress and water logging was studied in pot condition. Lower root length with higher dry weight were observed in the well-watered plants, on the other hand, shorter root length with lower dry weight was in the waterlogged plants compared to the water-stressed plants. Wellwatered plants had the highest, water-stressed plants had the lowest and waterlogged plants had the intermediate values for plant height and fresh stem weight. All the leaves of the waterlogged plants were shed at 90 days after planting. The water-stressed plants had higher shoot-root ratio followed by the well-water and waterlogged plants.
\end{abstract}

Keywords: Mulberry, soil moisture, leaf yield, root characters.

\section{Introduction}

Soil moisture directly influences soil-water relationships, aeration and permeability. The effect of drying and re-watering of soil plays a major role on the growth, nutrient uptake and distribution of plants (Nazrul-Islam, 1977). Flooding reduces water absorption directly by decreasing the permeability of root to water and indirectly by reducing the size of the root system. The restricted root development under water logging is due to anaerobic respiration (Ponnamperuma, 1972).

Mulberry forms the basic food material for silkworms and the bulk of the silk goods produced in the world are from mulberry silkworms. Mulberry is perennial woody plant, it can hardly tolerate water logging for several weeks and on the other hand, it can withstand prolonged drought. Though moisture is necessary for growth of mulberry plant, but if the surplus moisture is prolonged, the mulberry plants starve and ultimately they die.

The experiment was designed to gain information on the effect of low, normal and excess soil moisture on root growth and leaf yield of five mulberry varieties.

\section{Materials and methods}

Five improved mulberry varieties used in the experiment were BM-1, BM-2, BM3 , BM-4 and BM-5. The experiment was conducted in pot condition. The earthen pots were $35 \mathrm{~cm}$ in height and $50 \mathrm{~cm}$ in diameter at the top and $20 \mathrm{~cm}$ at the bottom. Each pot was filled with sandy loam soil $(20 \mathrm{~kg})$ mixed with organic manure (cow-dung). Pots were arranged in a randomized block design with three replications.

Three soil moisture regimes were as follows: well-watered (WW) - normal watering as and when necessary, water-stress (WS) - watering at the wilting point and waterlogged (WL) - dipping the pots under water (30 days of water logging). 
Plants were allowed to grow well; normal watering was done as and when necessary up to 90 days for treatment of WW. For WS, water was added normally up to 30 days after planting (DAP) and after that it was subjected to stress condition, where water was added at the wilting point only. For WL, plants were allowed to grow well up to 60 DAP, where normal watering was done but after 60 DAP, they were subjected to waterlogged condition up to 90 DAP. In this treatment, pots were placed in the earthen bowls where pots were flooded in submerging with tap water and water level was maintained at $2-3 \mathrm{~cm}$ above thee soil surface of the pots.

At 90 DAP, all these treated plants were uprooted carefully without damaging the root system. Roots were washed thoroughly to remove all the soil particles adhering to them. The following characters were recorded: maximum root length, root dry weight, plant height, leaf size, stem weight and leaf yield. Due to shedding of leaves, no leaf character was recorded for the waterlogged treatment. For the measurement of dry weights of root, stem and leaf, these were dried in an oven at $90{ }^{0} \mathrm{C}$ till they reached constant weight. Shoot-root ratio was also calculated from the shoot weight (leaf weight + stem weight) divided by root weight. Data were analysed statistically.

\section{Results and discussion}

Root characters: Longer root length and higher dry weight of roots were observed in the well-watered plants and shorter length with lower dry weight was in the waterlogged plants compared to the water-stressed plants (Table 1). Mean root length was longer in BM-3 followed by BM-2, BM-4, BM-1 and BM-5. The maximum root length of BM-5 always had the lowest value in all the three treatments. Higher root dry weight was found in BM-3, which was followed by $\mathrm{BM}-4, \mathrm{BM}-1, \mathrm{BM}-5$ and BM-2. BM-3 and BM-4 had the highest root dry weight in the well-watered, waterlogged and water-stressed plants and BM-2 always had the lowest root dry weight in these three treatments. Susheelema \& Jolly (1986) reported that plants with deep roots also had higher root mass. Reddy \& Sudhakar (1990) reported that reduction in dry matter of roots and leaves was due to water stress. Anonymous (1975) in mulberry reported that root growth was mainly depended on the adequate water content of the soil. Water stress was found to reduce the weight of roots produced in wheat (Saha \& Paul, 1995). Flooding reduces water absorption directly by decreasing the permeability of root to water and indirectly by reducing the size of the root system. The restricted root development under waterlogging was due to anaerobic respiration.

Among the varieties, BM-3 had better performance in the well-watered and waterlogged conditions and BM-4 in the water-stressed condition (Table 1). So among the three soil moisture treatments and five mulberry varieties, the wellwatered treatment and BM-3 were the best for the root characters.

Leaf yield and component characters : Significant effect of soil moisture on plant height and leaf size were found (Table 1). The highest and the lowest plant height were found in the well-watered and water-stressed plants, respectively. Greater and smaller leaf size was observed in the well-watered and water-stressed plants, respectively, but as leaves were shed in the waterlogged treatment at 90 DAP, no record was possible (Table 1). Kasiviswanathan \& Iyengar (1965) also reported that taller plants were observed in the well-watered and shorter in the water-stressed treatments. Other workers also reported increased plant height due to irrigation and shorter plant height due to shortage of soil moisture (Allen et al., 1976). 
Table 1. Root characters and leaf yield and its components of five mulberry varieties as influenced by soil moisture.

\begin{tabular}{|c|c|c|c|c|c|c|}
\hline Treatment & BM-1 & BM-2 & BM-3 & BM-4 & BM-5 & Mean \\
\hline \multicolumn{7}{|c|}{ Root length (cm) } \\
\hline WW & 58.00 & 61.00 & 57.00 & 56.40 & 48.00 & 56.08 \\
\hline WS & 48.00 & 49.00 & 50.00 & 50.50 & 43.00 & 48.10 \\
\hline WL & 41.00 & 43.40 & 47.00 & 43.00 & 40.50 & 42.98 \\
\hline Mean & 49.00 & 51.13 & 51.33 & 49.97 & 43.83 & \\
\hline \multirow{2}{*}{\multicolumn{7}{|c|}{ a) 0.71 b) 0.92 c) 1.60 Root dry weight (g) }} \\
\hline & & & & & & \\
\hline WW & 6.98 & 5.10 & 8.25 & 6.71 & 6.05 & 6.62 \\
\hline WS & 2.90 & 2.36 & 3.12 & 3.36 & 2.82 & 2.91 \\
\hline WL & 2.10 & 2.06 & 2.95 & 2.93 & 1.95 & 2.40 \\
\hline Mean & 3.99 & 3.17 & 4.77 & 4.33 & 3.61 & \\
\hline \multirow{2}{*}{\multicolumn{7}{|c|}{ a) 0.16 b) 0.21 c) 0.36 Plant height $(\mathrm{cm})$}} \\
\hline & & & & & & \\
\hline WW & 76.30 & 64.90 & 62.70 & 61.50 & 60.60 & 65.20 \\
\hline WS & 52.20 & 45.40 & 44.00 & 44.00 & 38.00 & 44.72 \\
\hline WL & 64.30 & 53.90 & 50.70 & 51.70 & 45.00 & 53.12 \\
\hline Mean & 64.27 & 54.73 & 52.47 & 52.40 & 47.87 & \\
\hline LSD 5\% & a) 1.34 & .73 с) 3.01 & & & & \\
\hline \multicolumn{7}{|c|}{ Leaf size $\left(\mathrm{cm}^{2}\right)$} \\
\hline WW & 160.00 & 110.00 & 105.90 & 185.80 & 165.00 & 1145.34 \\
\hline WS & 120.00 & 85.00 & 80.00 & 140.00 & 130.80 & 111.16 \\
\hline WL & - & - & - & - & & - \\
\hline Mean & 93.33 & 65.00 & 61.66 & 108.60 & 98.60 & \\
\hline \multirow{2}{*}{\multicolumn{7}{|c|}{$\begin{array}{l}\text { a) } 3.40 \text { b) } 4.47 \text { c) } 7.74 \\
\text { Fresh stem weight/plant (g) }\end{array}$}} \\
\hline & & & & & & \\
\hline WW & 45.90 & 35.00 & 35.70 & 42.40 & 39.20 & 39.64 \\
\hline WS & 34.00 & 27.00 & 24.90 & 30.00 & 28.00 & 28.78 \\
\hline WL & 35.00 & 28.20 & 29.00 & 32.00 & 29.50 & 30.74 \\
\hline Mean & 38.30 & 30.07 & 29.87 & 34.80 & 32.23 & \\
\hline \multirow{2}{*}{\multicolumn{7}{|c|}{$\begin{array}{l}\text { a) } 0.89 \text { b) } 1.15 \text { c) } 1.99 \\
\text { Stem dry weight/plant (g) }\end{array}$}} \\
\hline & & & & & & \\
\hline WW & 17.20 & 13.70 & 13.20 & 15.10 & 13.60 & 14.56 \\
\hline WS & 12.85 & 11.30 & 9.60 & 10.60 & 11.00 & 11.07 \\
\hline WL & 8.75 & 8.00 & 7.20 & 9.20 & 7.50 & 8.13 \\
\hline Mean & 12.93 & 11.00 & 10.00 & 11.63 & 10.70 & \\
\hline \multirow{2}{*}{\multicolumn{7}{|c|}{ 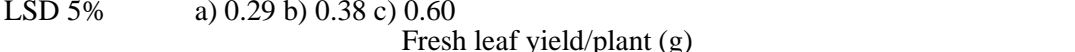 }} \\
\hline & & & & & & \\
\hline WW & 52.00 & 44.00 & 53.00 & 65.50 & 63.00 & 55.50 \\
\hline WS & 36.20 & 30.33 & 37.00 & 45.00 & 42.00 & 38.11 \\
\hline WL & - & - & - & - & - & - \\
\hline Mean & 29.40 & 24.77 & 30.00 & 36.83 & 35.00 & \\
\hline LSD 5\% & a) $1.09 \mathrm{~b}$ & 04 c) 2.45 & & & & \\
\hline \multicolumn{7}{|c|}{ Dry leaf yield/plant (g) } \\
\hline WW & 14.60 & 12.40 & 15.30 & 16.40 & 16.00 & 14.94 \\
\hline WS & 11.50 & 9.90 & 12.50 & 14.40 & 16.00 & 14.94 \\
\hline WL & - & - & - & - & - & - \\
\hline Mean & 8.70 & 7.43 & 9.26 & 10.26 & 9.66 & \\
\hline LSD 5\% & a) $0.47 \mathrm{~b}$ & 60 c) 0.74 & & & & \\
\hline \multicolumn{7}{|c|}{ Shoot-root ratio } \\
\hline WW & 4.56 & 5.12 & 3.45 & 4.69 & 4.89 & 4.54 \\
\hline WS & 8.40 & 8.98 & 7.08 & 7.44 & 8.51 & 8.08 \\
\hline WL & 4.17 & 3.88 & 2.44 & 3.14 & 3.85 & 3.49 \\
\hline Mean & 5.71 & 5.99 & 4.32 & 5.09 & 5.75 & \\
\hline LSD 5\% & a) 0.44 & .66 c) 0.24 & & & & \\
\hline
\end{tabular}

a) Treatment means b) Varietal means c) Treatment - variety interaction. 
Greater leaf size in the well-watered and smaller in the water-stressed plants confirmed the findings of Hsiao (1973) and Rangaswami et al. (1976). In the waterlogged condition, shedding and rotting of leaf were similar to that reported by Aruga (1994) in mulberry. Among the varieties, BM-1 and BM-4 had the highest plant height and leaf size, respectively.

Higher fresh and dry weights of stem and leaf were found in the well-watered plants than the water-stressed and waterlogged plants (Table 1). Poor result was observed in the water-stressed plants for stem fresh weight, but not for dry weight, which was poor in the waterlogged plants. Higher stem weight and leaf yield in the well-moistured treatment confirmed the findings of Rangaswami et al. (1976), Kasiviswanathan \& Iyengar (1965) and Kasiviswanathan (1979). Lower stem weight and leaf yield in the water-stressed plants were similar with the findings of Mukherjee et al. (1972) in mulberry, Prasad et al. (1990) in green gram and Khan \& Paul (1993) in rape. Shoot dry matter decreased due to water stress was reported by Pandey et al. (1991). In the waterlogged treatment, mulberry leaves were shed, which is in line with Aruga (1994). Among the treatments and varieties, wellwater and BM-1 and BM-4 had higher stem weight and leaf yield/plant, respectively.

Shoot-root ratio was higher in the water-stressed plants than the well-watered plants and poor in the waterlogged plants (Table 1). But Nazrul-Islam and Alam (1987) in jute reported reverse result. Shoot to root ratios by length and by dry weight are best for selection. Among the varieties, BM-2 in the well-watered and water-stressed conditions and BM-1 in the waterlogged condition had higher shoot-root ratio.

\section{References}

Allen, L.H., Boote, K.J. \& Hammond, L.C. 1976. Peanut stomatal diffusion resistance affected by soil moisture and solar radiation. Proceedings Soil and Crop Science Society, 35: 42-46.

Anonymous. 1975. Text book of tropical sericulture. Japan Overseas Cooperation Volunteers, Tokyo: 91-92.

Aruga, H. 1994. Disorder in mulberry. Oxford \& IBH Publishing Co., Bombay.

Hsiao, T.C. 1973. Plant responses to water. Annual Review of Plant Physiology, 24:519-570.

Kasiviswanathan, K. \& Iyengar, M.N.S. 1965. Preliminary observation on varietal cum irrigational response to different levels of $\mathrm{N}$ on the seasonal and total yield of mulberry leaf. Indian Journal of Sericulture, 4:22-33.

Kasiviswanathan, K. 1979. Annual report. Central Sericultural Research \& Training Institute, Mysore: 33-38.

Khan, M.R. \& Paul, N.K. 1993. Effect of soil moisture on growth attributes, physiological characters and yield of mustard (Brassica juncea L.). Proceedings $7^{\text {th }}$ Botanical Conference. 95-101.

Mukherjee, S.K., Ray, D. \& Pain. A.K. 1972. Influence of different levels of irrigation on the yield of bushy mulberry raised under Bengal and Mysore system of plantation. Indian Journal of Sericulture, 11:33-38.

Nazrul-Islam, A.K.M. 1977. Comparative ecology of plants in relation to soil moisture and mineral nutrition. Ph.D. thesis. University of Shefield. 
Nazrul-Islam, A.K.M \& Alam, A.K.M.M. 1987. Comparative ecology of jute in relation to environmental factors. II Growth of two cultivars of jute in relation to soil moisture. Indian Journal of Plant Science, 5:26-32.

Pandey, R.P., Nair, P.K.R. \& Tiwari, J.P. 1981. Correlation of morpho-physiological and sink parameters in cowpea. Indian Journal of Agricultural Sciences, 51: 221-224

Ponnamperuma, F.N. 1972. The chemistry of submerged soil. Advances in Agronomy, 24: 39-96.

Prasad, U.K., Thakur, H.C., Prasad, T.N. \& Pandey, R.U. 1990. Effect of different irrigation schedules on yield, yield attributes and water use in green gram (Phaseolus rectatus). Indian Journal of Agricultural Sciences, 60: 732-734.

Rangaswami, G.M., Narasimahanna, M.N., Kasiviswanathan, K. \& Sastry, C.R. 1976. Sericulture manual. 1. Mulberry cultivation. FAO, Rome.

Reddy, P.S. \& Sudhakar,C. 1992. Modification levels of inorganic ions and dry matters in local and K-2 mulberry varieties under low soil moisture regimes. Indian Journal of Plant Physiology, 35:341-344.

Saha, S.K. \& Paul, N.K. 1995. Growth of five wheat cultivars (Triticum aestivum L.) as affected by soil moisture. Journal of Bioscience, 3:103-112.

Susheelamma, B.N. \& Jolly, M.S. 1986. Evaluation of morpho-physiological parameters associated with drought resistance in mulberry. Indian Journal of Sericulture, 25:6-14. 